\title{
openheart Improvements of predictive power of B- type natriuretic peptide on admission by mathematically estimating its discharge levels in hospitalised patients with acute heart failure
}

\author{
Eiji Anegawa (D) , ${ }^{1}$ Hiroyuki Takahama (D) , ${ }^{1}$ Kunihiro Nishimura, ${ }^{2}$ \\ Daisuke Onozuka (1) ,2 Yuki Irie, ${ }^{1}$ Kenji Moriuchi, ${ }^{1}$ Masashi Amano, ${ }^{1}$ \\ Atsushi Okada (D) , ${ }^{1}$ Makoto Amaki, ${ }^{1}$ Hideaki Kanzaki, ${ }^{1}$ Teruo Noguchi (D) , ${ }^{1}$ \\ Kengo Kusano (D) , ${ }^{1}$ Satoshi Yasuda, ${ }^{1}$ Chisato Izumi ${ }^{1}$
}

\section{- Additional supplemental material is published online only. To view, please visit the journal online (http://dx.doi.org/10.} 1136/openhrt-2021-001603).

To cite: Anegawa $\mathrm{E}$, Takahama H, Nishimura K, et al. Improvements of predictive power of B-type natriuretic peptide on admission by mathematically estimating its discharge levels in hospitalised patients with acute heart failure Open Heart 2021;8:e001603. doi:10.1136/ openhrt-2021-001603

Received 25 January 2021 Revised 9 March 2021 Accepted 6 April 2021

D Check for updates

C Author(s) (or their employer(s)) 2021. Re-use permitted under CC BY. Published by BMJ.

${ }^{1}$ Department of Cardiovascular Medicine, National Cerebral and Cardiovascular Center, Suita Japan

${ }^{2}$ Department of Preventive Medicine and Epidemiology, National Cerebral and Cardiovascular Center, Suita, Japan

\section{Correspondence to} Dr Hiroyuki Takahama; takahama@cardio.med.tohoku. ac.jp

\section{ABSTRACT}

Backgrounds Earlier studies showed that in patients with heart failure (HF), circulating levels of B-type natriuretic peptide (BNP) at hospital discharge $\left(\mathrm{BNP}_{\text {dis }}\right)$ are more predictive of prognosis than BNP levels on admission $\left(\mathrm{BNP}_{\mathrm{ad}}\right)$. However, the mechanism underlying that difference has not been fully elucidated. We examined the association between confounding factors during hospitalisation and $\mathrm{BNP}_{\text {dis }}$ in patients with HF. Methods We identified patients admitted to our hospital for HF (BNP ${ }_{\text {ad }} \geq 100 \mathrm{pg} / \mathrm{mL}$ ). Estimated left ventricular end-diastolic pressure (eLVEDP) was calculated using echocardiographic data. To identify the factors associated with the relation between $\mathrm{BNP}_{\mathrm{ad}}$ and $\mathrm{BNP}_{\mathrm{dis}}$, we performed a stepwise regression analysis of retrospective data. To validate that analysis, we performed a prospective study. Results Through stepwise regression of the patient data ( $n=688$, New York Heart Association 3-4, 88\%), we found age, blood urea nitrogen and eLVEDP to be significantly $(p<0.05)$ associated with $\mathrm{BNP}_{\text {dis. }}$. Through multivariate analysis after accounting for these factors, we created a formula for predicting BNP levels at discharge (predicted$\mathrm{BNP}_{\text {dis }}$ ) from $\mathrm{BNP}_{\mathrm{ad}}$ and other parameters measured at admission $(p<0.05)$. By statistically adjusting for these factors, the prognostic power of BNP $_{\text {ad }}$ was significantly improved $(p<0.001)$. The prospective study also confirmed the strong correlation between predicted-BNP ${ }_{\text {dis }}$ and $\mathrm{BNP}_{\text {dis }}$ $(\mathrm{n}=104, \mathrm{r}=0.625, \mathrm{p}<0.05)$.

Conclusion This study showed that statistically accounting for confounding factors affecting BNP levels improves the predictive power of BNP levels measured at the time of hospital admission, suggesting that these confounding factors are associated with lowering predictive power of BNP on admission. Trial registration number UMIN $000034409,00035428$.

\section{INTRODUCTION}

B-type natriuretic peptide (BNP) is widely used as a predictive biomarker in patients

\section{Key questions}

What is already known about this subject?

- Predictive power of B-type natriuretic peptide (BNP) levels at hospital admission $\left(\mathrm{BNP}{ }_{\mathrm{ad}}\right)$ is inferior to that of BNP levels at discharge $\left(\mathrm{BNP}_{\text {dis }}\right)$ in patients with acute heart failure (HF). However, the mechanism underlying these differences has not been fully elucidated.

What does this study add?

- Through multivariate analysis after accounting for known confounding factors related to circulating BNP levels, we created a formula for predicting BNP levels at discharge (predicted-BNP ${ }_{\text {dis }}$ ) from BNP and other parameters measured at admission.

- This study showed that statistically accounting for confounding factors affecting BNP levels improves the predictive power of BNP levels measured at the time of hospital admission.

How might this impact on clinical practice?

- This predicted-BNP ${ }_{\text {dis }}$ has superior predictive power for clinical outcomes to BNP . This may contribute to the risk stratification of acute HF and primary intensive care management in acute vulnerable phases of HF.

with heart failure (HF). ${ }^{1}$ However, earlier studies showed that in patients with acute $\mathrm{HF}$, the predictiveness of BNP levels measured at hospital admission $\left(\mathrm{BNP}_{\text {ad }}\right)$ for clinical outcomes is inferior to BNP levels measured at discharge $\left(\mathrm{BNP}_{\mathrm{dis}}\right){ }^{23}$ Although the reason for the insufficient predictive power of $\mathrm{BNP}_{\mathrm{ad}}$ compared with $\mathrm{BNP}_{\text {dis }}$ in these patients has not been fully elucidated, several confounding factors are well known to influence circulating BNP levels (eg, left ventricular end-diastolic pressure (LVEDP) 
and renal function) ${ }^{4-7}$ However, how these parameters influence the lower predictability of $\mathrm{BNP}_{\mathrm{ad}}$ than that of $\mathrm{BNP}_{\text {dis }}$ remains uncertain.

Given the importance of clinical risk stratification for hospitalised patients with heterogeneous clinical syndromes, this study aimed to identify the confounding factors affecting $\mathrm{BNP}_{\text {ad }}$ that are associated with $\mathrm{BNP}_{\text {dis }}$. We also tested the hypothesis: whether statistical adjustments of these confounding factors are related to predictive power of $\mathrm{BNP}_{\mathrm{ad}}$ improvements in patients with acute HF.

\section{METHODS}

\section{Study design}

This was a cross-sectional study of patients with HF admitted to the National Cerebral and Cardiovascular Center of Japan.

\section{Study population}

\section{Retrospective study}

Included in the retrospective study were 688 patients hospitalised for HF between January 2013 and March 2016 (BNP on admission: $\geq 100 \mathrm{pg} / \mathrm{mL}$ ). We excluded patients who did not undergo a blood test and echocardiography, who underwent implantation of a left ventricular (LV) assist device $(n=3)$, or who died in the hospital $(n=24)$ during the corresponding hospitalisation. We also excluded patients who underwent mitral valve surgery $(n=85)$ due to its influence on transmitral flow and septal mitral annular velocity.

Diagnosis of HF was based on the Framingham criteria. ${ }^{8}$ Whether or not a HF episode met the Framingham criteria was determined by each attending physician and an investigator (H Takahama) via medical record review. We excluded patients who did not meet the criteria, as judged by the investigator and the attending physician for each patient. According to the guidelines of the Japanese Circulation Society, ${ }^{9}$ we defined the cut-off value of plasma BNP level for diagnosis of $\mathrm{HF}$ as $100 \mathrm{pg} / \mathrm{mL}$.

\section{Prospective study}

We prospectively collected data from 104 patients between January and June in 2019 based on the same criteria used for the retrospective study.

\section{Echocardiography}

Through medical chart review, we retrospectively reviewed the echocardiography data collected during the hospitalisation. LV dimensions were measured according to the American Society of Echocardiography guidelines. ${ }^{10} \mathrm{LV}$ ejection fraction (EF) was measured using the modified Simpson method or the semiquantitative twodimensional visual estimate method, as described previously. ${ }^{11}$ Transmitral inflow was measured with pulsedwave Doppler using standard methods as described previously. ${ }^{12}$ The septal mitral annular early diastolic velocity $\left(\mathrm{e}^{\prime}\right)$ was determined with spectral tissue Doppler imaging. LVEDP was calculated as $11.96+0.596 \times$ early diastolic transmitral flow velocity (E)/ $\mathrm{e}^{\prime}$, as previously reported. ${ }^{13}$

\section{Measurement of plasma BNP concentration}

All biochemical analyses were performed as routine clinical examinations. BNP were measured by human brain natriuretic peptide kit (TOSOH corporation, Tokyo, Japan).

\section{Clinical outcomes}

After the admission date, we investigated through medical chart review or a letter all causes of death and rehospitalisation for HF. Combined clinical events were defined as all-cause death or rehospitalisation for HF.

\section{Ethics}

The study was designed to be carried out without obtaining individual informed consent according to the 'opt-out' principle. Instead, we publicised a summary of the study protocol with the contact information for our office on the institution website, which provided patients with the ability to refuse enrolment to the study. This study protocol was also registered in the Japanese University Hospital Medical Information Network Clinical Trials Registration.

\section{Statistical analyses}

Results are expressed as the median and IQR. Fisher's exact test or the $\chi^{2}$ test was used to compare categorical variables, as appropriate. With regard to baseline patient characteristics, Wilcoxon's rank-sum test was used for comparison of continuous variables between two groups. HRs with 95\% CIs and probability $(\mathrm{p})$ values determined using the likelihood ratio test are presented. The area under the receiver operating characteristics (ROC) curve (AUC) and C-statistics were also calculated. AUCs were compared using an algorithm developed by DeLong et $a l^{14}$ Pairwise comparisons of the areas under multiple ROC curves were made using the roccomp command in Stata. Multivariate analysis/regression was used to test multiple covariates. All tests were two tailed, and values of $\mathrm{p}<0.05$ were considered significant. All statistical analyses were performed using JMP V.9 statistical analysis software (SAS Institute Japan, Inc, Tokyo, Japan) and Stata V.15 (Stata Corporation LLC, College Station, Texas, USA).

\section{RESULTS \\ Retrospective data analysis}

Using the inclusion and exclusion criteria described in the Methods section, we identified 688 patients with HF from our database. The patient characteristics on admission were as follows (table 1): New York Heart Association class III and IV on admission, $43 \%$ and $45 \%$, respectively; median LVEF: 35\% (IQR: 24\%-55\%); median LV end-diastolic diameter (LVEDD), $56 \mathrm{~mm}$ (IQR: 48-64 mm); and median plasma BNP levels, $671 \mathrm{pg} / \mathrm{mL}$ (IQR: $370-1170 \mathrm{pg} / \mathrm{mL}$ ). Median hospitalisation length was 19.5 days (IQR: 14-27 days). The patients treated without beta-blockers were often observed in those with valvular regurgitation and with $\mathrm{HF}$ with preserved EF. Based on earlier studies, we selected the following clinical 


\begin{tabular}{ll}
\hline Table 1 & Baseline patient characteristics \\
\hline & Overall patients \\
\hline Patients number & 688 \\
\hline Age (years) & $78(69-84)$ \\
Gender (male) & $429(62)$ \\
\hline BMl (kg/m²) & $22.5(20.2-25.4)$ \\
\hline NYHA class & \\
\hline Class III & $296(43)$ \\
Class IV & $311(45)$ \\
\hline Aetiology & \\
Ischaemic & $232(34)$ \\
\hline Non-ischaemic & $172(25)$ \\
Valvular & $98(14)$ \\
\hline Hypertensive & $149(22)$ \\
\hline Others & $37(5)$ \\
\hline
\end{tabular}

\section{History}

\begin{tabular}{ll}
\hline Hypertension & $490(71)$ \\
\hline Atrial fibrillation & $345(50)$ \\
\hline Diabetes mellitus & $250(36)$ \\
\hline
\end{tabular}

\section{Vital signs and others on admission}

\begin{tabular}{ll}
\hline Systolic blood pressure $(\mathrm{mm} \mathrm{Hg})$ & $120(105-138)$ \\
\hline Diastolic blood pressure $(\mathrm{mm} \mathrm{Hg})$ & $68(58-81)$ \\
\hline Heart rate $(\mathrm{bpm})$ & $77(66-92)$ \\
\hline Echocardiography & \\
\hline LVEDD (mm) & $56(48-64)$ \\
\hline LVESD (mm) & $44(34-54)$ \\
\hline LVEF $(\%)$ & $35(24-55)$ \\
\hline E/e' & $14.4(10.6-19.4)$ \\
\hline eLVEDP (mm Hg) & $20.5(18.3-23.5)$ \\
\hline Laboratory data & \\
\hline BNP ${ }_{\text {ad }}(\mathrm{pg} / \mathrm{mL})$ & $671(370-1170)$ \\
\hline BNP ${ }_{\text {dis }}(\mathrm{pg} / \mathrm{mL})$ & $280(153-468)$ \\
\hline eGFR (mL/min/1.73 m²) & $46(30-60)$ \\
\hline BUN (mg/dL) & $24(18-34)$ \\
\hline Hb (g/dL) & $12.2(10.7-13.4)$ \\
\hline Hct $(\%)$ & $37(33-41)$ \\
\hline CRP (mg/dL) & $0.35(0.12-1.20)$ \\
\hline WCC $\left(\times 10^{3} / \mathrm{uL}\right)$ & $6.4(5.1-8.0)$ \\
\hline T-Cho (mg/dL) & $154(130-178)$ \\
\hline HDL-C (mg/dL) & $42(34-51)$ \\
\hline LDL-C (mg/dL) & $88(70-110)$ \\
\hline Medications & \\
\hline On admission & \\
\hline ACEi or ARB & $418(61)$ \\
\hline Beta-blockers & \\
\hline Aldosterone antagonists & \\
\hline Loop diuretics & \\
\hline
\end{tabular}

Table 1 Continued

\begin{tabular}{ll}
\hline & Overall patients \\
\hline Dobtamin & $68(10)$ \\
At discharge & \\
\hline ACEi or ARB & $516(75)$ \\
Beta-blockers & $539(78)$ \\
\hline Aldosterone antagonists & $297(43)$ \\
Loop diuretics & $585(85)$ \\
Median observation period (days) & $623(188-730)$ \\
\hline
\end{tabular}

Values are the median (IQR) and patients number, $\mathrm{n}(\%)$. ACEi, ACE inhibitor; ARB, angiotensin II receptor blocker; BMI, body mass index; $\mathrm{BNP}_{\mathrm{ad}}$, circulating $\mathrm{B}$-type natriuretic peptide levels on admission; $\mathrm{BNP}_{\text {dis }}$, circulating B-type natriuretic peptide levels at hospital discharge; BUN, blood urea nitrogen; CRP, $C$ reactive protein; eGFR, estimated glomerular filtration rate; eLVEDP, estimated left ventricular end-diastolic pressure; $\mathrm{Hb}$, haemoglobin; Hct, haematocrit; HDL-C, high-density lipoprotein cholesterol; LDL-C, low-density lipoprotein cholesterol; LVEDD, left ventricular end-diastolic diameter; LVEF, left ventricular ejection fraction; LVESD, left ventricular end-systolic diameter; NYHA, New York Heart Association; T-cho, total cholesterol; WCC, white cell count.

parameters known to influence circulating BNP levels for analysis: age, sex,${ }^{4}$ LVEDP ${ }^{515}$ blood pressure,${ }^{16}$ heart rate, ${ }^{7}$ body mass index (BMI) $,{ }^{6} \mathrm{LVEF},{ }^{17} 18$ end-diastolic volume,${ }^{17}$ LVEDD,${ }^{18}$ cholesterol levels,${ }^{19}$ anaemia,${ }^{20}$ renal function, ${ }^{720}$ atrial fibrillation ${ }^{21}$ and diabetes mellitus. ${ }^{22}$ The results of univariate analyses of the association between $\mathrm{BNP}_{\text {dis }}$ and the selected parameters are shown in table 2. Age, BMI, systolic blood pressure, diastolic blood pressure, LVEDD, LVEF, estimated LVEDP (eLVEDP), estimated glomerular filtration, blood urea nitrogen (BUN), haemoglobin, hematocrit, total cholesterol and low-density lipoprotein cholesterol on admission were all associated with $\mathrm{BNP}_{\text {dis }}$ after adjusting for $\mathrm{BNP}_{\text {ad }}$. Stepwise analysis identified the following parameters as significantly associated with $\mathrm{BNP}_{\text {dis }}$ after accounting for $\mathrm{BNP}_{\mathrm{ad}}$ levels: age, systolic blood pressure, LVEF, eLVEDP and BUN levels (table 3). Subsequent multivariate analysis revealed the parameter estimates of the above factors to be: 3.81 (age), -1.09 (systolic blood pressure), -0.87 (LVEF), 6.72 (eLVEDP), $3.48(\mathrm{BUN})$ and $0.21\left(\mathrm{BNP}_{\mathrm{ad}}\right)$. Using those data, we developed the following formula to predict $\mathrm{BNP}_{\text {dis }}$ from $\mathrm{BNP}_{\text {ad }}$ : the 'predicted $-\mathrm{BNP}_{\text {dis }}$ ' $=3.81 \times$ age $-1.09 \times$ systolic blood pressure $-0.87 \times \mathrm{LVEF}+6.72 \times$ $\mathrm{eLVEDP}+3.48 \times \mathrm{BUN}+0.21 \times \mathrm{BNP}_{\mathrm{ad}}-184.5$. Next, the analysis of association non-pharmacological intervention on the relation between the parameters used for estimation of the predicted- $\mathrm{BNP}_{\text {dis }}$ and $\mathrm{BNP}_{\text {dis }}$ were performed because the therapeutic intervention might influence the discharge levels of BNP. As shown in online supplemental table 1, no statistical significance was found. In addition, there was significant differences in both $\mathrm{BNP}_{a d}$ and $\mathrm{BNP}_{\text {dis }}$ in patients with initial admission and rehospitalisation for HF. As shown in online supplemental table 2, both BNP levels were higher in patients with readmission than 
Table 2 Association of discharge levels of BNP with clinical parameters on admission (univariate analysis)

\begin{tabular}{llr}
\hline Variables & \multicolumn{1}{l}{$\boldsymbol{r}$} & P value \\
\hline Age & 0.1550 & $<0.0001$ \\
\hline Gender & \multicolumn{1}{l}{ n/a } & 0.3940 \\
\hline BMI $\left(\mathrm{kg} / \mathrm{m}^{2}\right)$ & -0.2167 & $<0.0001$ \\
\hline Atrial fibrillation & $\mathrm{n} / \mathrm{a}$ & 0.1084 \\
\hline Diabetes mellitus & $\mathrm{n} / \mathrm{a}$ & 0.9110 \\
\hline Systolic blood pressure $(\mathrm{mm} \mathrm{Hg})$ & -0.1109 & 0.0036 \\
\hline Diastolic blood pressure $(\mathrm{mm} \mathrm{Hg})$ & -0.0875 & 0.0220 \\
\hline Heart rate $(\mathrm{bpm})$ & -0.0657 & 0.0854 \\
\hline LVEDD $(\mathrm{mm})$ & 0.1084 & 0.0045 \\
\hline LVEF $(\%)$ & -0.1822 & $<0.0001$ \\
\hline eLVEDP $(\mathrm{mm} \mathrm{Hg})$ & 0.1460 & 0.0001 \\
\hline BNP ${ }_{\text {ad }}(\mathrm{pg} / \mathrm{mL})$ & 0.5779 & $<0.0001$ \\
\hline eGFR $\left(\mathrm{mL} / \mathrm{min} / 1.73 \mathrm{~m}^{2}\right)$ & -0.3153 & $<0.0001$ \\
\hline BUN $(\mathrm{mg} / \mathrm{dL})$ & 0.3438 & $<0.0001$ \\
\hline Hb $(\mathrm{g} / \mathrm{dL})$ & -0.1635 & $<0.0001$ \\
\hline Hct $(\%)$ & -0.1529 & $<0.0001$ \\
\hline T-Cho $(\mathrm{mg} / \mathrm{dL})$ & -0.1312 & 0.0006 \\
\hline HDL-C $(\mathrm{mg} / \mathrm{dL})$ & -0.0362 & 0.3476 \\
\hline LDL-C $(\mathrm{mg} / \mathrm{dL})$ & -0.0793 & 0.0388 \\
\hline
\end{tabular}

Abbreviations are shown in table 1.

those in initial admission. The correlation of the predicted$\mathrm{BNP}_{\text {dis }}$ with $\mathrm{BNP}_{\text {dis }}$ was similar between the patients with initial admission and readmission $(\mathrm{p}<0.05)$.

During the follow-up period (median: 623 days, IQR: 188-730 days), combined clinical events occurred in

\begin{tabular}{lr}
\hline $\begin{array}{l}\text { Table } 3 \text { Stepwise regression analysis for association of } \\
\text { BNP }_{\text {dis }} \text { with variables on admission }\end{array}$ \\
\hline Variables & P value \\
\hline Age & 0.0004 \\
BMl $\left(\mathrm{kg} / \mathrm{m}^{2}\right)$ & 0.7260 \\
\hline Systolic blood pressure $(\mathrm{mm} \mathrm{Hg})$ & 0.0074 \\
\hline Diastolic blood pressure $(\mathrm{mm} \mathrm{Hg})$ & 0.4822 \\
LVEDD $(\mathrm{mm})$ & 0.1740 \\
LVEF $(\%)$ & 0.0157 \\
\hline eLVEDP $(\mathrm{mm} \mathrm{Hg})$ & 0.0066 \\
eGFR $\left(\mathrm{mL} / \mathrm{min} / 1.73 \mathrm{~m}^{2}\right)$ & 0.6155 \\
\hline BUN $(\mathrm{mg} / \mathrm{dL})$ & $<0.0001$ \\
Hb $(\mathrm{g} / \mathrm{dL})$ & 0.0656 \\
\hline Hct $(\%)$ & 0.4669 \\
\hline T-Cho $(\mathrm{mg} / \mathrm{dL})$ & 0.6299 \\
LDL-C $(\mathrm{mg} / \mathrm{dL})$ & 0.7344 \\
\hline
\end{tabular}

Stepwise regression analysis for association of $\mathrm{BNP}_{\text {dis }}$ with variables on admission after accounting for $\mathrm{BNP}_{\mathrm{ad}}$. Abbreviations are shown in table 1.
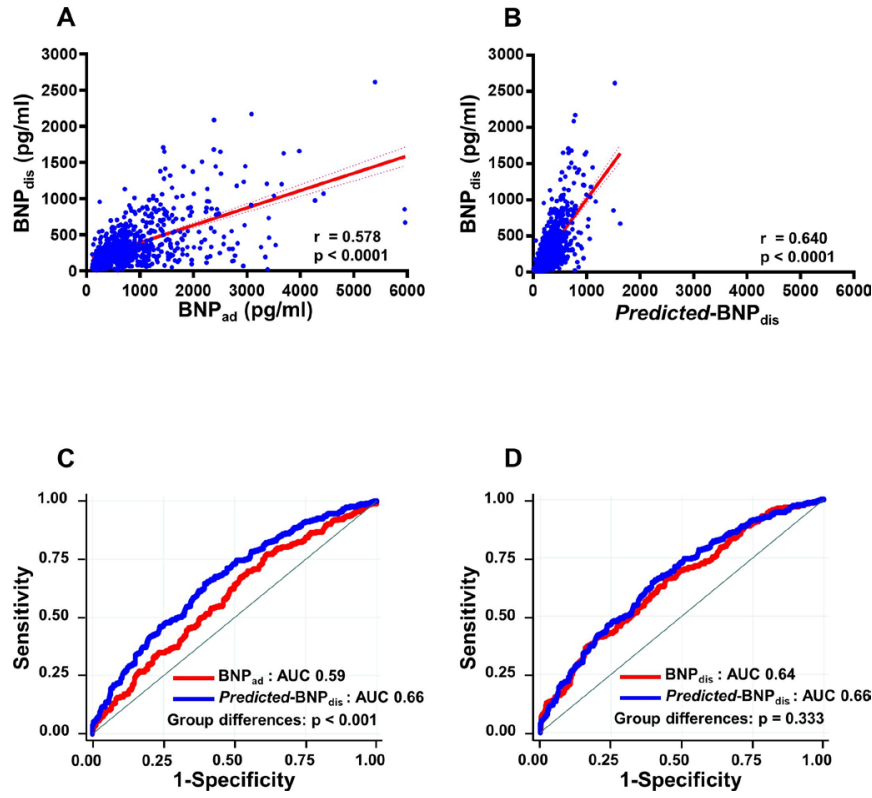

Figure 1 Association between BNP levels at hospital discharge and levels on admission or predicted BNP levels at discharge (predicted-BNP ${ }_{\text {dis }}$ ) and their prognostic power. (A) Correlation between circulating BNP levels at hospital discharge $\left(\mathrm{BNP}_{\text {dis }}\right)$ and $\mathrm{BNP}$ on admission $\left(\mathrm{BNP}_{\mathrm{ad}}\right)$. (B) Correlation between $\mathrm{BNP}_{\text {dis }}$ and predicted $\mathrm{BNP}$ levels at discharge (predicted-BNP ${ }_{\text {dis }}^{\text {is }}$ ).(C) Area under the receiver operating characteristics curve (AUC) analysis of the occurrence of the combined clinical events. AUC for the predicted BNP levels at discharge (predicted-BNP ${ }_{\text {dis }}$ : blue)

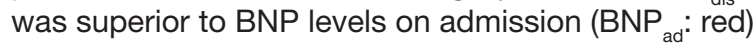
$(p<0.001)$. (D) There was no significant difference in the AUC for the predicted-BNP $P_{\text {dis }}$ (blue) and BNP levels at discharge $\left(\mathrm{BNP}_{\text {dis }}\right.$ : red). $\mathrm{BNP}_{\mathrm{ad}}$, B-type natriuretic peptide on hospital admission; $\mathrm{BNP}_{\mathrm{dis}}$, $\mathrm{B}$-type natriuretic peptide at discharge.

$295(43 \%)$ patients: all causes of death $(\mathrm{n}=68,10 \%)$ and rehospitalisation for $\mathrm{HF}(\mathrm{n}=227,33 \%)$. Figure 1 shows the correlation between $\mathrm{BNP}_{\text {dis }}$ and $\mathrm{BNP}_{\text {ad }}$ (figure 1A) and between $\mathrm{BNP}_{\text {dis }}$ and predicted- $\mathrm{BNP}_{\text {dis }}$ (figure $1 \mathrm{~B}$ ). However, AUC analysis showed that predicted $-\mathrm{BNP}_{\text {dis }}$ was significantly more predictive of outcome than $\mathrm{BNP}_{\mathrm{ad}}$ $(\mathrm{p}<0.001)$ and was comparable with the predictiveness of $\mathrm{BNP}_{\text {dis }}$ (figure 1C,D).

\section{Prospective data analysis}

The prospective study revealed similar relationships between $\mathrm{BNP}_{\text {ad }}$ or predicted $-\mathrm{BNP}_{\text {dis }}$ and $\mathrm{BNP}_{\text {dis }}$ (figure $2 \mathrm{~A}, \mathrm{~B}$ ).

\section{DISCUSSION}

Circulating BNP levels are affected by a number of confounding factors during the acute phase of HF and are associated with fluctuations in measured BNP levels during the initial few days after hospital admission or intensive treatments. ${ }^{23} 24$ These fluctuations are mainly due to changes in ventricular preload and the systemic fluid overload state. Our retrospective study confirmed known confounding factors affecting BNP levels and showed that these factors statistically were associated with 


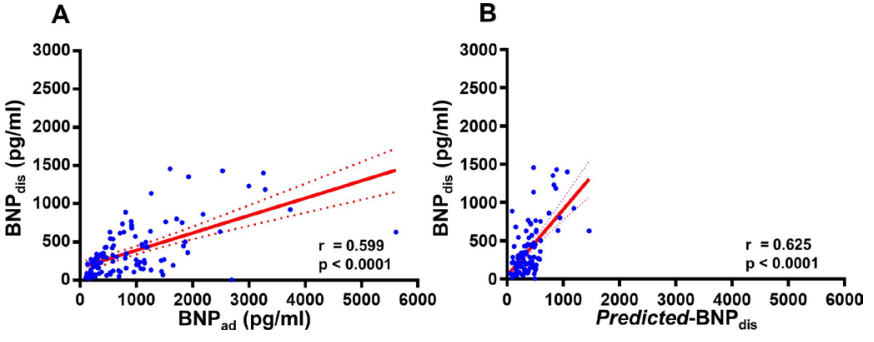

Figure 2 Association between BNP levels at hospital discharge and levels on admission or predicted BNP levels at discharge (predicted-BNP ${ }_{\text {dis }}$ ) in a prospective study. (A) Correlation between circulating BNP levels at hospital discharge $\left(\mathrm{BNP}_{\mathrm{dis}}\right)$ and $\mathrm{BNP}$ levels on admission $\left(\mathrm{BNP}_{\mathrm{ad}}\right)$. (B) Correlation between BNP ${ }_{\text {dis }}$ and predicted BNP levels at discharge (predicted-BNP ${ }_{\text {dis }}$ ). Note the similarity between the results of the prospective and retrospective studies. $\mathrm{BNP}_{\mathrm{ad}}$, $\mathrm{B}$-type natriuretic peptide on hospital admission; $\mathrm{BNP}_{\mathrm{dis}}, \mathrm{B}$ type natriuretic peptide at discharge.

lowering the predictive power of $\mathrm{BNP}_{\mathrm{ad}}$ levels for patient outcomes. This study also showed that after statistically accounting for these confounding factors, the predictive power of the resultant $\mathrm{BNP}$ value (predicted-BNP $\mathrm{Bis}_{\mathrm{dis}}$ ) did not significantly differ from that of $\mathrm{BNP}_{\mathrm{dis}}$. Moreover, the finding of the correlation of predicted- $\mathrm{BNP}_{\text {dis }}$ with $\mathrm{BNP}_{\mathrm{dis}}$ was validated by obtaining similar results in a prospective study.

Several earlier studies reported on the factors influencing circulating BNP levels. For example, Iwanaga et $a \tilde{l}^{\tilde{p}}$ measured LVEDP using a LV catheter system and clearly demonstrated that LV wall stress strongly correlated with plasma BNP levels. In addition, factors such as increased cardiac preload likely due to excess body fluid, which may stretch ventricular cardiomyocytes, sharply increases circulating BNP levels in patients with $\mathrm{HF}$. By the time $\mathrm{BNP}_{\text {dis }}$ levels are measured, however, the patient has reached an appropriate volume state through removal of the excess body fluid. Consequently, $\mathrm{BNP}_{\text {dis }}$ levels may more closely reflect myocardial quality per se or a 'true ventricular trait'. This may explain why $\mathrm{BNP}_{\mathrm{ad}}$ levels measured during the acute phase of HF have less predictive power than $\mathrm{BNP}_{\text {dis }}$ levels. In the present study, we observed that after accounting for several factors, including LVEDP and LVEF, as well as blood pressure and renal function, the predicted BNP levels, which we termed predicted-BNP ${ }_{\text {dis }}$, strongly correlated with $\mathrm{BNP}_{\text {dis }}$ levels and were equally predictive of patient outcome.

Thus, by determining the impact of factors responsible for the difference in predictive power between $\mathrm{BNP}_{\mathrm{ad}}$ and $\mathrm{BNP}_{\text {dis }}$, we were able to shed light on the relationship between these factors and $\mathrm{BNP}_{\text {dis }}$. These findings may further our understanding of BNP levels, which are influenced by various factors in patients with acute HF.

\section{Limitation}

The present study has several limitations. First, this was a single-centre investigation with a limited number of patients. Nevertheless, we were able to confirm a formula that predicts BNP levels at discharge from clinical parameters at the time of admission. Second, several patients did not undergo a blood test for BNP and E/e'; we excluded these patients from our analysis. Next, it is widely known that the therapeutic intervention might influence the discharge levels of BNP. These therapeutic interventions might also influence the relationship between the clinical parameters on admission with the $\mathrm{BNP}_{\text {dis }}$, although no statistical association were found in online supplemental table 1. Furthermore, this study enrolled the patients between 2013 and 2016, and at that time, sacubtrilvarsartan was not approved in Japan, which is known to influence circulating BNP levels. Further investigation will be necessary to confirm the effects of sacubtrilvarsartan on the predicted BNP levels at discharge. The association of the predicted- $\mathrm{BNP}_{\text {dis }}$ with $\mathrm{BNP}_{\text {dis }}$ is statistically significant, but the degree of correlation was modest; we could not exclude the possibility that the other unknown factor or therapeutic effects, which are not included for the estimation of $\mathrm{BNP}_{\text {dis }}$ in this study, might be also associated with the regulation of BNP. Taken together, this study was not designed to investigate the effects of the prospectively controlled pharmacological or non-pharamacological intervention on $\mathrm{BNP}_{\text {dis }}$. Further prospective study will be necessary to address these problems.

In addition, there was no discharge criteria for the research in this study, and in general, discharges were determined by the attending physician. Although the discharge levels are determined by clinical findings including BNP levels in stable phases of $\mathrm{HF}$, the variation of HF severity at discharge exists among the attending physicians, which might create the further variation of the discharge levels of BNP.

\section{CONCLUSION}

We have shown the confounding factors affecting measured BNP levels and demonstrated BNP prediction at discharge in hospitalised patients with HF. This predicted BNP values have superior predictive power for clinical outcomes to raw BNP values on admission. This may contribute to the risk stratification of acute HF and primary intensive care management in acute vulnerable phases of HF.

Acknowledgements The authors would like to thank the research coordinator and assistants in our institute for the data collection.

Contributors HT, EA, TN, KK, SY and Cl contribute to design of the work; HT, EA, $\mathrm{DO}, \mathrm{KN}$ contribute to the acquisition and analysis of data for the work; HT, EA, $\mathrm{HK}, \mathrm{SY}, \mathrm{Yl}, \mathrm{AO}, \mathrm{MA}, \mathrm{MA}, \mathrm{KM}$ and $\mathrm{Cl}$ contributed to drafting the work or revising it critically for important intellectual content; final approval was done by HT.

Funding This work was supported by the Intramural Research Fund of the National Cerebral and Cardiovascular Centre of Japan (grants 30-1-3 to Cl).

Competing interests None declared.

Patient consent for publication Not required.

Ethics approval The study protocol was approved by the institutional review bord of the National Cerebral and Cardiovascular Centre (M26-127 and M30-155).

Provenance and peer review Not commissioned; externally peer reviewed. Data availability statement № data are available. 
Open access This is an open access article distributed in accordance with the Creative Commons Attribution 4.0 Unported (CC BY 4.0) license, which permits others to copy, redistribute, remix, transform and build upon this work for any purpose, provided the original work is properly cited, a link to the licence is given, and indication of whether changes were made. See: https://creativecommons.org/ licenses/by/4.0/.

\section{ORCID iDs}

Eiji Anegawa http://orcid.org/0000-0003-1534-4431

Hiroyuki Takahama http://orcid.org/0000-0003-4155-1936

Daisuke Onozuka http://orcid.org/0000-0001-9596-9188

Atsushi Okada http://orcid.org/0000-0002-0087-4168

Teruo Noguchi http://orcid.org/0000-0001-5372-4932

Kengo Kusano http://orcid.org/0000-0002-5760-9285

\section{REFERENCES}

1 Chow SL, Maisel AS, Anand I, et al. Role of biomarkers for the prevention, assessment, and management of heart failure: a scientific statement from the American heart association. Circulation 2017;135:e1054-91.

2 Hamatani Y, Nagai T, Shiraishi Y, et al. Long-Term prognostic significance of plasma B-type natriuretic peptide level in patients with acute heart failure with reduced, Mid-Range, and preserved ejection fractions. Am J Cardiol 2018;121:731-8.

3 Bettencourt P, Azevedo A, Pimenta J, et al. N-terminal-pro-brain natriuretic peptide predicts outcome after hospital discharge in heart failure patients. Circulation 2004;110:2168-74.

4 Redfield MM, Rodeheffer RJ, Jacobsen SJ, et al. Plasma brain natriuretic peptide concentration: impact of age and gender. $J \mathrm{Am}$ Coll Cardiol 2002;40:976-82.

5 Iwanaga Y, Nishi I, Furuichi S, et al. B-type natriuretic peptide strongly reflects diastolic wall stress in patients with chronic heart failure: comparison between systolic and diastolic heart failure. J Am Coll Cardiol 2006;47:742-8

6 Horwich TB, Hamilton MA, Fonarow GC. B-type natriuretic peptide levels in obese patients with advanced heart failure. J Am Coll Cardiol 2006;47:85-90.

7 Tsutamoto T, Wada A, Sakai H, et al. Relationship between renal function and plasma brain natriuretic peptide in patients with heart failure. J Am Coll Cardiol 2006;47:582-6.

$8 \mathrm{Ho} \mathrm{KK}$, Anderson KM, Kannel WB, et al. Survival after the onset of congestive heart failure in Framingham heart study subjects. Circulation 1993;88:107-15.

9 Tsutsui $\mathrm{H}$, Isobe M, Ito H, et al. JCS 2017/JHFS 2017 guideline on diagnosis and treatment of acute and chronic heart Failure digest version. Circ J 2019;83:2084-184.

10 Lang RM, Bierig M, Devereux RB, et al. Recommendations for chamber quantification: a report from the American Society of echocardiography's guidelines and standards Committee and the chamber quantification writing group, developed in conjunction with the European association of echocardiography, a branch of the European Society of cardiology. J Am Soc Echocardiogr 2005;18:1440-63.

11 Imazu M, Takahama H, Asanuma $\mathrm{H}$, et al. Pathophysiological impact of serum fibroblast growth factor 23 in patients with nonischemic cardiac disease and early chronic kidney disease. Am J Physiol Heart Circ Physiol 2014;307:H1504-11.

12 Patel JB, Borgeson DD, Barnes ME, et al. Mitral regurgitation in patients with advanced systolic heart failure. J Card Fail 2004;10:285-91.

13 Lam CSP, Roger VL, Rodeheffer RJ, et al. Cardiac structure and ventricular-vascular function in persons with heart failure and preserved ejection fraction from Olmsted County, Minnesota. Circulation 2007;115:1982-90

14 DeLong ER, DeLong DM, Clarke-Pearson DL. Comparing the areas under two or more correlated receiver operating characteristic curves: a nonparametric approach. Biometrics 1988;44:837-45.

15 Maeda K, Tsutamoto T, Wada A, et al. Plasma brain natriuretic peptide as a biochemical marker of high left ventricular end-diastolic pressure in patients with symptomatic left ventricular dysfunction. Am Heart J 1998;135:825-32.

16 Kario K, Nishikimi T, Yoshihara F, et al. Plasma levels of natriuretic peptides and adrenomedullin in elderly hypertensive patients: relationships to $24 \mathrm{H}$ blood pressure. J Hypertens 1998;16:1253-9.

17 Yan RT, White M, Yan AT, et al. Usefulness of temporal changes in neurohormones as markers of ventricular remodeling and prognosis in patients with left ventricular systolic dysfunction and heart failure receiving either candesartan or enalapril or both. Am J Cardiol 2005;96:698-704.

18 Masson S, Latini R, Anand IS, et al. Direct comparison of Btype natriuretic peptide (BNP) and amino-terminal proBNP in a large population of patients with chronic and symptomatic heart failure: the valsartan heart failure (Val-HeFT) data. Clin Chem 2006;52:1528-38.

19 Takeuchi $\mathrm{H}$, Sata $\mathrm{M}$. The relationship among brain natriuretic peptide (BNP), cholesterol and lipoprotein. Heart Asia 2012;4:11-15.

20 Hogenhuis J, Voors AA, Jaarsma T, et al. Anaemia and renal dysfunction are independently associated with BNP and NT-proBNP levels in patients with heart failure. Eur J Heart Fail 2007;9:787-94.

21 Knudsen CW, Omland T, Clopton $\mathrm{P}$, et al. Impact of atrial fibrillation on the diagnostic performance of B-type natriuretic peptide concentration in dyspneic patients: an analysis from the breathing not properly multinational study. J Am Coll Cardiol 2005;46:838-44.

22 Gruden G, Landi A, Bruno G. Natriuretic peptides, heart, and adipose tissue: new findings and future developments for diabetes research. Diabetes Care 2014;37:2899-908.

23 Takahama H, Takashio S, Nishikimi T, et al. Ratio of pro-B-type natriuretic peptide (BNP) to total BNP is decreased in mild, but not severe, acute decompensated heart failure patients: a nove compensatory mechanism for acute heart failure. Int $\mathrm{J}$ Cardiol 2018;258:165-71.

24 Ito K, Kawai M, Nakane T, et al. Serial measurements associated with an amelioration of acute heart failure: an analysis of repeated quantification of plasma BNP levels. Eur Heart J Acute Cardiovasc Care 2012;1:240-7. 